\title{
HOW CAN RADIOACTIVE ELEMENTS HELP US?
}

\author{
RADIOCHEMISTRY INVOLVES MAKING MOLECULES WITH \\ RADIOACTIVE ATOMS. DR DAVIDE AUDISIO OF THE FRÉDÉRIC \\ JOLIOT INSTITUTE FOR LIFE SCIENCES, PART OF THE FRENCH \\ ALTERNATIVE ENERGIES AND ATOMIC ENERGY COMMISSION, \\ IS FINDING NEW WAYS TO USE THEM MORE EFFICIENTLY
}

\section{TALK LIKE A RADIOCHEMIST}

\section{RADIOCHEMISTRY - the chemistry of} natural and man-made unstable isotopes

ISOTOPE - variants of a chemical element that have the same number of protons but different numbers of neutrons

\section{RADIOLABELS - the addition of a} radioactive isotope to a molecule so that it can be traced and imaged

When did you last take a tablet? Perhaps, it was when you needed to ease a headache or control an allergy? From time to time, most of us do take tablets, but how often do we think about what happens to them after we have swallowed them? More importantly, how do pharmaceutical companies assess the effects of the drugs they produce and what happens to them when they enter our bodies?

"The impact of synthetic organic molecules on health, life quality and lifestyle is beyond doubt," says Dr Davide Audisio, of the Frédéric Joliot Institute for Life Sciences,
PROTONS - positively charged subatomic particles found in the nucleus of the atom

NEUTRONS - neutral particles found in the nucleus of the atom

METABOLISM - the chemical processes in cells that break down chemical compounds like food or medicine

part of The French Alternative Energies and Atomic Energy Commission (CEA), in France. "I $t$ is, therefore, of fundamental importance to detect and quantify the fate of organic compounds and provide a precise risk/benefit assessment, before they reach the market and large public exposure."

Davide is a radiochemist whose work is evidence of the positive and profound impact the science behind radioactive materials can have on our lives. He is working on the FASTLabEX project, making molecules that contain radiolabels so that they can be traced
- and so pharmaceuticals and chemicals can be developed and monitored, and safety ensured. Davide explains, "FASTLabEx will help the pharmaceutical industry to apply the new labelling methods to drugs currently in development in order to provide solutions to the most pressing problems in drug innovation." But the impact of Davide's work does not stop there - his project and his expertise as a radiochemist also has applications in crop science and food safety.

\section{RADIOLABELLING}

In pharmaceutical compounds, most drugs have what is called an active ingredient. The active ingredient is the molecule that has the desired medicinal effect. However, what happens between swallowing a tablet and the active ingredient entering our bloodstream and reaching its target is very complicated.

This is because the molecules that we take in the tablet can be metabolised by our cells and enzymes - broken down and changed into lots of other different molecules. Hopefully, molecules will be made that have the desired healing effect. However, sometimes other compounds are made that have unwanted side effects. 



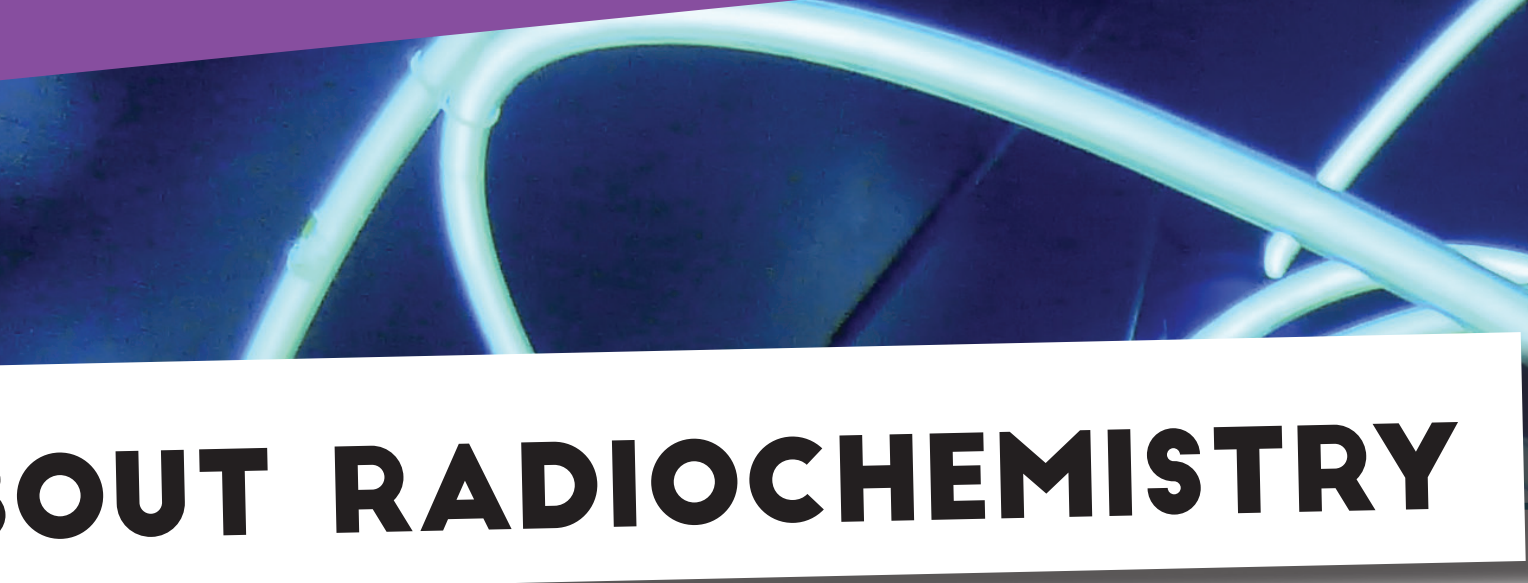

Radiochemistry is the study of radioactive materials. Most of the elements in the periodic table have several isotopes and many of these are radioactive.

Radiochemists work with those isotopes in a variety of different ways.

Some radiochemists, like Davide, are working to synthesise molecules with radioactive isotopes in them. While this is similar in some ways to the job of a synthetic chemist in a pharmaceutical company or university, these molecules are much more complicated to work with and radiochemists need to be trained in how to handle radioactive materials.

Other researchers work with archaeologists or oceanographers who use the information from radioisotopes to age objects and track how the ocean moves. Their work differs to Davide's as they measure the radioactivity but do not need to do chemistry with the radioelement. Some may work in hospitals, using different isotopes to help treat patients, and some may work at nuclear reactors, helping to find safe ways to deal with waste or make new isotopes.

Radiochemistry is a diverse field and many other professions rely on the knowledge and skills of radiochemists to support their work.

\section{WHAT DOES DAVIDE FIND MOST FASCINATING/REWARDING ABOUT CHEMISTRY?}

"The ability to construct organic molecules by breaking and creating new bonds is a very charming concept to me. The idea of being able to imitate nature is fascinating. For me, the most rewarding thing about chemistry is the teamwork involved. I have the privilege of working with a very talented group of people. Interacting with my colleagues is very enriching and constructive. I love when we find new ideas and solutions over these discussions."
WHAT ISSUES WILL BE FACING THE NEXT GENERATION OF CHEMISTS? "The next generation of chemists will have to face a series of challenges. In organic chemistry, there are still plenty of unsolved fundamental problems. In particular, they will need to find new solutions for making chemicals that will be environmentally friendly - they will need to harness 'green chemistry'."

\section{DOES THE FRÉDÉRIC}

JOLIOT INSTITUTE FOR LIFE SCIENCES OFFER ANY PUBLIC OUTREACH SCHEMES?

"One of our duties at CEA is to teach our expertise to young people and so we regularly have internship programmes with students. These can vary in format: programme lengths range from a short period of two weeks for high school students, to 6 months for master's students."

\section{EXPLORE A CAREER IN RADIOCHEMISTRY}

- Radiochemistry and nuclear chemistry are closely related. While direct work experience in radiochemistry may be difficult to get, you may be able to visit the nuclear medicine department of your local hospital or your local university.

- According to payscale.com, the average salary for a radiochemist in the UK is $£ 37,000$.

- According to salaryliost.com, the average salary for a radiochemist in the US is around $\$ 62,000$.

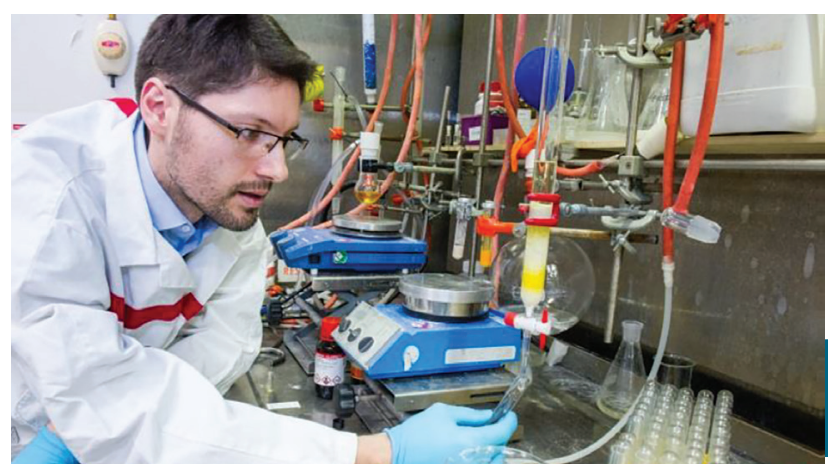

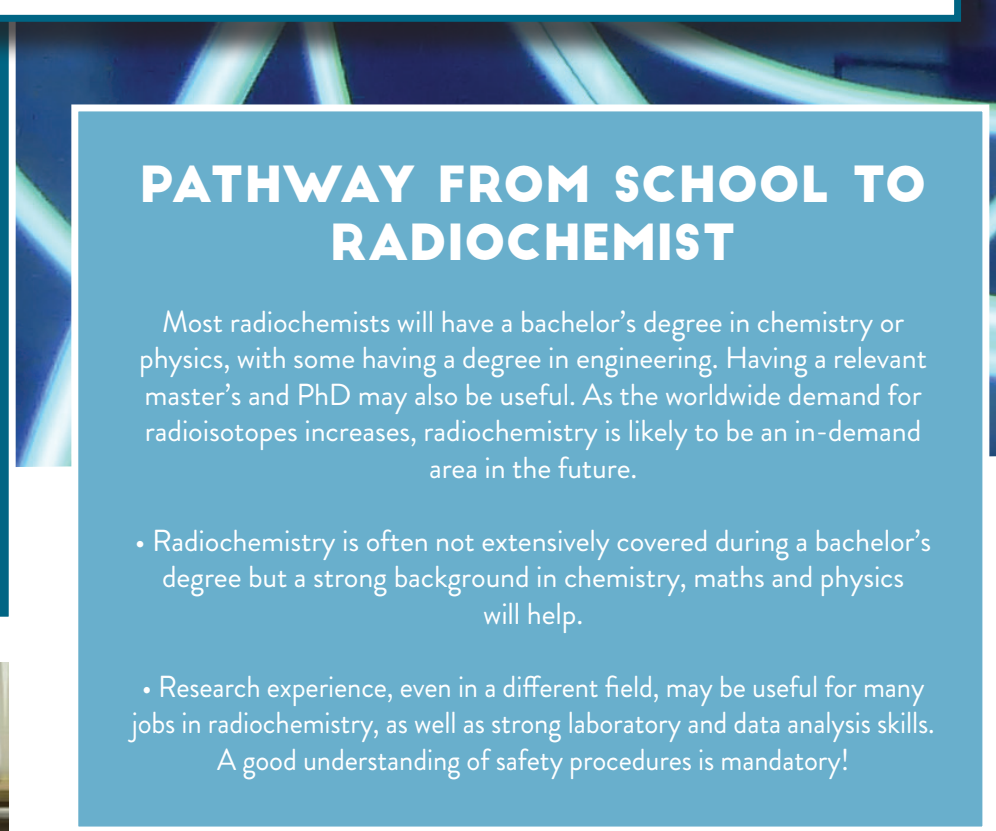

Purification of molecules from the reaction mixtures is a fundamental step in organic chemistry and radiolabelling. Davide is purifying a stable carbon-13 labelled compound by column chromatography. Credit: L. Godart/CEA 
